\title{
Acute symptomatic seizures and epilepsy after mechanical thrombectomy
}

Eriksson $\mathrm{H}^{1,2}$, Löwhagen Hendén $\mathrm{P}^{2,3}$, Rentzos $\mathrm{A}^{2,4}$, Pujol-Calderón $\mathrm{F}^{5}$, Karlsson $\mathrm{JE}^{1,2}$, Höglund $\mathrm{K}^{5,6}$, Blennow $\mathrm{K}^{5,6}$, Zetterberg $\mathrm{H}^{5,6,7,8}$, Rosengren $\mathrm{L}^{1,2}$, and Zelano $\mathrm{J}^{1,2 *}$

${ }^{1}$ Department of Clinical Neuroscience, Sahlgrenska Academy, University of Gothenburg

${ }^{2}$ Sahlgrenska University Hospital, Sweden. Blå stråket 7, 41346 Sweden.

${ }^{3}$ Department of Anesthesiology and Intensive Care, Sahlgrenska Academy, University of Gothenburg

${ }^{4}$ Department of Radiology, Institute of Clinical Sciences, Sahlgrenska Academy, University of Gothenburg

${ }^{5}$ Department of Psychiatry \& Neurochemistry, Institute of Neuroscience and Physiology, the Sahlgrenska Academy at the University of Gothenburg, Mölndal, Sweden

${ }^{6}$ Clinical Neurochemistry Laboratory, Sahlgrenska University Hospital, Mölndal, Sweden

${ }^{7}$ UK Dementia Research Institute at UCL, London, United Kingdom

${ }^{8}$ Department of Neurodegenerative Disease, UCL Institute of Neurology, London, United Kingdom

*Corresponding author: johan.zelano@neuro.gu.se

Manuscript type: Special issue Original article 
Declaration of interest: HZ has served at scientific advisory boards for Roche Diagnostics, Wave, Samumed and $\operatorname{CogRx}$, has given lectures in symposia sponsored by Biogen and Alzecure, and is a co-founder of Brain Biomarker Solutions in Gothenburg AB, a GU Ventures-based platform company at the University of Gothenburg (all outside submitted work). KB has served as a consultant or at advisory boards for Alector, Alzheon, CogRx, Biogen, Lilly, Novartis and Roche Diagnostics, and is a co-founder of Brain Biomarker Solutions in Gothenburg AB, a GU Venture-based platform company at the University of Gothenburg, all unrelated to the work presented in this paper. JZ reports consultancy fee from the Swedish Medical Products agency, and has been investigator/sub-investigator without personal compensation in clinical trials at Sahlgrenska university hospital sponsored by Bial, SK Life science, and GW Pharma. 


\section{Abstract (245 words)}

Purpose: To assess the incidence of acute symptomatic seizures and post-stroke epilepsy (PSE) in a well-characterized cohort of patients treated with mechanical thrombectomy. In addition, we aimed to describe the dynamics of blood markers of brain injury in patients that developed PSE.

Methods: Participants of the prospective AnStroke Trial of anesthesia method during mechanical thrombectomy were included and acute symptomatic seizures and PSE ascertained by medical records review. Blood markers NFL, tau, GFAP, S100B, and NSE were assessed.

Results: A total of 90 patients with acute anterior ischemic stroke were included. Median NIHSS at admission to hospital was 18 (IQR 15-22). Recanalization was achieved in 90\%. No patients had epilepsy prior to the ischemic stroke. Four patients $(4.4 \%)$ had acute symptomatic seizures and four patients $(4.4 \%)$ developed PSE during the follow-up time (to death or last medical records review) of 0 - 4.5 years (median follow-up 1070 days IQR 7771306), resulting in a two-year estimated PSE risk of 5.3\% (95\%CI: 0.2-10.4\%). Blood markers of brain injury (NFL, tau, GFAP, S100B, and NSE) were generally above the cohort median in patients that developed PSE.

Conclusions: The incidence of PSE after mechanical thrombectomy was low in our cohort. All blood biomarkers displayed interesting sensitivity and specificity. However, the number of PSE cases was small and more studies are needed on risk factors for PSE after mechanical thrombectomy. The potential of blood markers of brain injury markers to contribute to assessment of PSE risk should be explored further.

Keywords: epilepsy, stroke, rehabilitation 


\section{Introduction}

Emergency revascularization is the most important intervention in acute stroke care, with endovascular mechanical thrombectomy (hereinafter thrombectomy) being superior to systemic intravenous thrombolysis for large vessel occlusion [1, 2]. Since stroke severity and cortical involvement - a hallmark feature of embolic stroke - are risk factors for post-stroke epilepsy (PSE) [3-5], candidates for thrombectomy could, at least before successful revascularization, also be at a high risk of subsequent PSE.

There is more information on the occurrence of seizures after revascularization for patients that have received thrombolysis than for patients that have undergone thrombectomy. Reported rates of acute symptomatic seizures (seizures within one week of stroke) in thrombolysis-treated patients vary from approximately $1 \%$ to $15 \%$ [6-9]. In three relatively recent studies of thrombolysis-treated cohorts, PSE (seizures occurring $>1$ week after stroke) was reported in 5.8\%-16.7\% [6, 10, 11]. After thrombectomy, acute symptomatic seizures have been described in $2.4 \%$ [12]. In a large multicenter study of patients receiving different revascularization treatments, PSE occurred in $12.9 \%$ of patients receiving only intra-arterial therapy (thrombectomy or intra-arterial thrombolysis) and treatment was associated with an increased risk of PSE, also with adjustments for stroke severity assessed by mRS [10].

With an increasing number of patients undergoing thrombectomy, more information on the risk of subsequent PSE is important. Ideally, biomarkers for patients at risk should also be identified. We investigated the incidence of acute symptomatic seizures and PSE in participants in the randomized trial AnStroke, which compared sedation vs. general anesthesia in patients undergoing thrombectomy without any demonstrable difference between the groups [13]. During the trial, blood samples were collected for analyses of five blood markers reflecting brain injury in acute stroke [14-17]; we explored their potential as biomarkers for high PSE risk. 


\section{Material and methods}

\subsection{Study cohort}

The AnStroke Trial included 90 patients aged 18 or older with acute anterior circulation stroke suitable for thrombectomy. The trial evaluated differences in stroke outcome depending on whether the patient had sedation or general anesthesia during thrombectomy, and no such difference was detected [13]. Participants were recruited prospectively from Sahlgrenska University Hospital between 2013 and 2016. The inclusion criteria were NIHSS score $>10$ for right-sided occlusion or $>14$ for left-sided occlusion. Treatment was initiated within 8 hours after first showing of symptoms and patients were not included if mRS (modified Rankin scale) score $>4$ or if neurological recovery or recanalization occurred before or during angiography. Patients were excluded if there were any contraindications to thrombectomy. Infarction volume estimation was made by Computed Tomography (CT) at day 1 in 88 (98\%) of patients, and Magnetic Resonance Imaging (MRI) was performed in 77 patients $(86 \%)$ at day 3 . Neuroimaging was assessed by several neuroradiologists. In addition to volume measures and anatomical descriptions, lesions were classified according to the Alberta stroke program early CT score (ASPECTS).

\subsection{Blood sampling and biochemical analyses.}

Blood samples were drawn longitudinally on arrival, at 2h, 24h, $48 \mathrm{~h}, 72 \mathrm{~h}$, and at three months or later following thrombectomy. Samples were stored at $-80 \mathrm{C}$ after aliquotation. Tau and GFAp concentrations were measured using commercially available tau or GFAp kit Single molecule array (Simoa) 2.0 assays, as described by the manufacturer (Quanterix, Lexington, MA). NFL concentrations were measured using NFL ELISA kit from UmanDiagnostics (NF-light ${ }^{\circledR}$ ELISA kit, UmanDiagnostics AB) and moved to a Simoa assay, as previously described [18]. Concentrations of NSE and S100B were determined using 
immunoassays with electrochemiluminescence detection on the Elecsys platform (Roche Diagnostics, Penzberg, Germany).

\subsection{Ascertainment of seizures and PSE}

Medical records were reviewed and information on seizures was collected into a pre-defined case report form during the spring of 2018. The electronic medical records system in the region covers all hospitals with emergency and neurology departments. Seizures that occurred within seven days after stroke were defined as acute symptomatic seizures and unprovoked seizures occurring more than seven days after stroke were defined as PSE, in agreement with the current ILAE clinical definitions of acute symptomatic seizures and epilepsy $[19,20]$. The follow-up time (to death or last medical records review) was $0-4.5$ years (median follow-up 1070 days IQR 777-1306).

\subsection{Statistical analysis}

Data were analyzed using IBM SPSS Statistics for Macintosh, version 25.0. Continuous characteristics such as NIHSS score, time, and volumes, were calculated as median (IQR). Categorical values were presented as counts (proportions). Comparison between patients who developed epilepsy versus patients with acute symptomatic seizures was presented as median and compared using Independent Sample T-test. Statistical significance was defined as 2sided $\mathrm{p}<0.05$. For Cox and Kaplan-Meier analysis, time was calculated from stroke to PSE with censoring at death or 31/05/2018 (last date of medical records review). Cumulative risks were estimated with Kaplan-Meier survival tables and 95\%CI calculated as $1.96 \mathrm{x}$ standard error. Receiver Operating Characteristics (ROC) curves for blood biomarkers were created to evaluate their capacity to discriminate PSE patients from non-PSE patients (patients with acute symptomatic seizures were excluded from this analysis). The cutoff value for each 
putative biomarker was first assessed visually, and then more precisely calculated by Youden $\mathrm{J}$ index. Sensitivity and specificity were calculated.

\subsection{Ethical approval}

The regional board of ethics in Gothenburg approved the study (approval no EPN 013-13).

Patients or their relatives provided written informed consent. 


\section{Results}

\subsection{Study population}

Ninety patients with acute ischemic stroke that participated in AnStroke between 2013 and 2016 were included. Baseline characteristics are shown in Table 1. No patients had epilepsy prior to their stroke. One patient had a previous history of an acute symptomatic seizure provoked by alcohol.

\subsection{Seizures}

Four patients $(4.4 \%)$ had acute symptomatic seizures, none of these patients developed subsequent PSE. All acute symptomatic seizures occurred within the first three days with a median latency of 1.5 (IQR 0.5-2.5) days. Four (4.4\%) patients developed PSE (Fig. 1). The median latency until PSE was 211 (IQR 33-495) days. The Kaplan-Meier estimated risk of PSE was $3.9 \%$ (95\%CI: 0.0-8.2\%) at one year and 5.3\% (95\%CI: 0.2-10.4\%) at two years.

\subsection{Clinical characteristics and the risk of PSE}

Clinical details on each PSE patient are shown in Table 2. All patients with PSE had successful recanalization. Out of the four patients that developed PSE, all had NIHSS scores at discharge above the median of the study cohort. Two PSE patients had substantial reductions in NIHSS scores after thrombectomy and their infarction volumes on day three were below the cohort median. One patient that later developed PSE had an early stroke recurrence. Patients with acute symptomatic seizures and PSE were not significantly different regarding median age ( 78 vs $77, \mathrm{p}=0.85$ ), NIHSS score on admission (19 vs $22, \mathrm{p}=0.5$ ), or NIHSS after three days (12 vs $9, \mathrm{p}=0.42$ ), or regarding stroke volumes ( 5 vs $59, \mathrm{p}=0.38$ ). No baseline characteristic was significantly associated with an increased HR of PSE in univariate Cox regression ( $p>0.05$ ); age: HR 1.04 (95\%CI: 0.95-1.13), NIHSS at 
baseline: HR 1.17 (95\%CI: 0.92-1.5), time to recanalization: HR 1.00 (95\%CI 0.99-1.02), NIHSS at discharge: HR 1.04 (95\%CI: 0.94-1.15), infarction volume day 1: HR 1.01 (95\%CI: 1.00-1.02), or infarction volume day 3: HR 1.01 (95\%CI: 1.00-1.02).

\subsection{Anesthesiologic agents used during thrombectomy}

Regarding anesthesiologic agents during thrombectomy, two patients who developed acute symptomatic seizures received general anesthesia induced with propofol and maintained with remifentanil infusion and sevoflurane. Two patients who developed acute symptomatic seizures received conscious sedation with lower dosages of remifentanil infusion. Three patients who developed PSE received conscious sedation and one received general anesthesia.

\subsection{Blood biomarkers}

All patients that developed PSE had increased levels of blood markers at some point in time

(Fig. 2). The concentrations of blood markers in PSE patients were generally above the cohort median. The capacity of brain blood markers to identify PSE patients was explored by ROC analysis. At 48 hours, all four patients who developed epilepsy had a tau concentration $>14,045 \mathrm{pg} / \mathrm{mL}$, the optimal cutoff resulting in $100 \%$ sensitivity and $73 \%$ specificity. The remaining blood markers had optimal cutoff values at three months or later (at the later time points, blood was only available from two patients who subsequently developed PSE). With a sensitivity of $100 \%$, the best specificity for NFL, GFAP, S100B, or NSE was $77 \%-93 \%$. Although specificity was high, the number of events was small and no further statistical analysis was performed. 


\section{Discussion}

We describe the incidence of acute symptomatic seizures and PSE in a well-characterized cohort of patients following thrombectomy. Our main finding is that only $4 / 90$ patients $(4.4 \%)$ developed PSE. The survival-adjusted risk of PSE at two years was 5.3\% in our cohort, which is not very different from general stroke cohorts [4]. The literature on risk of PSE after mechanical thrombectomy is currently scarce. The incidence in our cohort is slightly lower than that recently reported in another study that followed patients up to two years, in which 17/205 (8.3\%) developed PSE after intra-arterial thrombolysis or thrombectomy, with or without previous intravenous thrombolysis [10]. Importantly, the authors did not specify which patients underwent mechanical thrombectomy, which limits comparability. The PSE rates reported in that study and ours do not exceed that of some cohorts treated with only intravenous thrombolysis, but there are probably substantial differences between thrombolysis-treated patients in general and patients selected for thrombectomy [6, 11].

In our study, 4/90 patients (4.4\%) developed acute symptomatic seizures. This is similar to previously reported rates for patients treated with intravenous thrombolytics without thrombectomy $[7,8]$, but reports range from $1 \%$ to $15 \%[6,9]$. So far, described risks of acute symptomatic seizures or PSE after thrombectomy are relatively low - given that patients selected for therapy are often at risk of very large lesions. There are currently conflicting results regarding whether reperfusion therapies per se are associated with an increased risk of PSE $[6,10]$. Publication of data from more cohorts should resolve this issue in the future. Meta-analyses of several cohorts could also focus on risk factors for PSE, which could facilitate recognition and early diagnosis. We could not identify any clinical or radiological factors significantly associated with an increased risk of PSE. In stroke patients in general, regardless of treatment, most studies have found stroke severity to be a risk factor for PSE [3, 4, 21], but we did not see any significant association between baseline NIHSS, or NIHSS at discharge, and subsequent PSE. Stroke severity, assessed as baseline NIHSS and 
$\mathrm{mRS}$ at follow-up, was also not significantly associated with a higher risk of PSE after revascularization treatment in the cohort described by Naylor [10]. Two studies have failed to demonstrate associations between outcome measures and PSE which suggests that other factors than just lesion size may have an impact on PSE risk after thrombectomy; candidate mechanisms include the degree of cortical involvement, microhaemorrhages, inflammatory response, genetic vulnerability, or blood-brain barrier disruption. There was now obvious association between particular anesthesiologic agents during thrombectomy and subsequent seizures. All anesthetics may dose-dependently induce seizures, barbiturates in particular have been associated with excitatory effects [22], but the material in our study is to small to be very informative in this matter.

To our knowledge, we also publish the first description of brain injury blood markers of patients that developed PSE. Brain injury blood markers can potentially reflect lesion characteristics not demonstrable on neuroimaging, which may improve understanding of PSE epileptogenesis. Most markers reach a maximum value after a few days [14, 23, 24], but NFL can continue to increase for weeks [25]. Analysis of the markers in relation to stroke outcome in the AnStroke cohort is in progress (Pujol-Calderón et al. in preparation). Within the cohort, several blood markers demonstrated good specificity and sensitivity for subsequent PSE. Interestingly, some markers had their optimal discriminative ability months after stroke, indicating that temporal factors like an extended response to injury may be of importance. Although the number of patients that developed PSE was too low for meaningful statistical analysis, the observations merit further study. Some blood markers alone or in combination could be of value in estimating PSE risk. More studies on the dynamics of markers may provide neurobiological insight into epileptogenesis and if a particular "blood marker profile" is associated with high PSE risk. 
There are limitations to our study. Ascertainment of epilepsy should be robust, since all hospitals with neurology service in the region share the same electronic medical records system. Generalizability is more questionable. Since the patients participated in a randomized trial of anesthesia form, they were considered suitable for both sedation and general anesthesia. This could mean selection of a healthier cohort than thrombectomy patients in general. The vital parameters of participants were very closely monitored peri-procedureally and systolic blood pressure before recanalization specifically targeted to $140-180 \mathrm{mmHg}$ [13]. The rate of recanalization was also high. Whether conditions during thrombectomy influence PSE risk is an interesting topic for future studies, especially since lesion size does not seem to be the sole determinant of PSE risk.

In summary, we report a relatively low risk of PSE following thrombectomy in the AnStroke trial. The knowledge on risks of PSE after revascularization is limited and more studies are needed. Register-based studies in countries with comprehensive registers or regions with large insurance databases could provide further insight. There is also a need for studies on the impact of potentially modifiable risk factors related to thrombectomy, such as intra-arterial blood pressure or cortical penumbra/lesion. All blood biomarkers displayed interesting sensitivity and specificity. These findings suggest that tau could be measured in acute settings and NFL, GFAP, S100B, and NSE later for evaluation of risk of PSE. Blood markers of brain injury should be studied further as putative biomarkers for predicting PSE.

\section{Acknowledgements}

Mattias Molin, Statistiska konsultgruppen, Gothenburg, provided statistical advice. 


\section{Funding}

Swedish Society of Medicine, Swedish Society for Medical Research, Jeansssons foundation, Magnus Bergvall foundation, Felix Neubergh foundation, Region Västra Götaland. HZ is a Wallenberg Academy Fellow supported by grants from the Swedish Research Council (\#2018-02532), the European Research Council (\#681712) and Swedish State Support for Clinical Research (\#ALFGBG-720931). KB holds the Torsten Söderberg Professorship in Medicine at the Royal Swedish Academy of Sciences, and is supported by the Swedish Research Council (\#2017-00915), the Swedish Alzheimer Foundation (\#AF-742881), Hjärnfonden, Sweden (\#FO2017-0243), and a grant (\#ALFGBG-715986) from the Swedish state under the agreement between the Swedish government and the County Councils, the ALF-agreement. 


\section{References}

[1] Berkhemer OA, Fransen PS, Beumer D, van den Berg LA, Lingsma HF, Yoo AJ, Schonewille WJ, Vos JA, Nederkoorn PJ, Wermer MJ, van Walderveen MA, Staals J, Hofmeijer J, van Oostayen JA, Lycklama a Nijeholt GJ, Boiten J, Brouwer PA, Emmer BJ, de Bruijn SF, van Dijk LC, Kappelle LJ, Lo RH, van Dijk EJ, de Vries J, de Kort PL, van Rooij WJ, van den Berg JS, van Hasselt BA, Aerden LA, Dallinga RJ, Visser MC, Bot JC, Vroomen PC, Eshghi O, Schreuder TH, Heijboer RJ, Keizer K, Tielbeek AV, den Hertog HM, Gerrits DG, van den Berg-Vos RM, Karas GB, Steyerberg EW, Flach HZ, Marquering HA, Sprengers ME, Jenniskens SF, Beenen LF, van den Berg R, Koudstaal PJ, van Zwam WH, Roos YB, van der Lugt $A$, van Oostenbrugge RJ, Majoie CB, Dippel DW, Investigators MC. A randomized trial of intraarterial treatment for acute ischemic stroke. N Engl J Med 2015;372: 11-20.

[2] Saver JL, Goyal M, Bonafe A, Diener HC, Levy El, Pereira VM, Albers GW, Cognard C, Cohen DJ, Hacke W, Jansen O, Jovin TG, Mattle HP, Nogueira RG, Siddiqui AH, Yavagal DR, Baxter BW, Devlin TG, Lopes DK, Reddy VK, du Mesnil de Rochemont R, Singer OC, Jahan R, Investigators SP. Stent-retriever thrombectomy after intravenous t-PA vs. t-PA alone in stroke. N Engl J Med 2015;372: 2285-95.

[3] Zelano J, Redfors P, Asberg S, Kumlien E. Association between poststroke epilepsy and death: A nationwide cohort study. European Stroke Journal 2016;1: 272-278.

[4] Graham NS, Crichton S, Koutroumanidis M, Wolfe CD, Rudd AG. Incidence and associations of poststroke epilepsy: the prospective South London Stroke Register. Stroke 2013;44: 605-11.

[5] Jungehulsing GJ, Heuschmann PU, Holtkamp M, Schwab S, Kolominsky-Rabas PL. Incidence and predictors of post-stroke epilepsy. Acta Neurol Scand 2013;127: 427-30. [6] Bentes C, Martins H, Peralta AR, Morgado C, Casimiro C, Franco AC, Fonseca AC, Geraldes R, Canhao P, Pinho EMT, Paiva T, Ferro JM. Epileptic manifestations in stroke patients treated with intravenous alteplase. Eur J Neurol 2017;24: 755-761.

[7] Feher G, Gurdan Z, Gombos K, Koltai K, Pusch G, Tibold A, Szapary L. Early seizures after ischemic stroke: focus on thrombolysis. CNS Spectr 2019: 1-13.

[8] Couillard P, Almekhlafi MA, Irvine A, Jette N, Pow J, St Germaine-Smith C, Pillay N, Hill $\mathrm{MD}$. Subacute seizure incidence in thrombolysis-treated ischemic stroke patients. Neurocrit Care 2012;16: 241-5.

[9] Xu Y, Hackett ML, Chalmers J, Lindley RI, Wang X, Li Q, Robinson T, Arima H, Lavados $\mathrm{PM}$, Anderson CS. Frequency, determinants, and effects of early seizures after thrombolysis for acute ischemic stroke: The ENCHANTED trial. Neurol Clin Pract 2017;7: 324-332.

[10] Naylor J, Thevathasan A, Churilov L, Guo R, Xiong Y, Koome M, Chen Z, Chen Z, Liu X, Kwan $\mathrm{P}$, Campbell BCV. Association between different acute stroke therapies and development of post stroke seizures. BMC Neurol 2018;18: 61.

[11] De Reuck J, Van Maele G. Acute ischemic stroke treatment and the occurrence of seizures. Clin Neurol Neurosurg 2010;112: 328-31.

[12] Anadani M, Lekoubou A, Almallouhi E, Alawieh A, Chatterjee A, Vargas J, Spiotta AM. Incidence, predictors, and outcome of early seizures after mechanical thrombectomy. J Neurol Sci 2019;396: 235-239.

[13] Lowhagen Henden P, Rentzos A, Karlsson JE, Rosengren L, Leiram B, Sundeman H, Dunker D, Schnabel K, Wikholm G, Hellstrom M, Ricksten SE. General Anesthesia Versus Conscious Sedation for Endovascular Treatment of Acute Ischemic Stroke: The AnStroke Trial (Anesthesia During Stroke). Stroke 2017;48: 1601-1607. 
[14] Bitsch A, Horn C, Kemmling Y, Seipelt M, Hellenbrand U, Stiefel M, Ciesielczyk B, Cepek L, Bahn E, Ratzka P, Prange H, Otto M. Serum tau protein level as a marker of axonal damage in acute ischemic stroke. Eur Neurol 2002;47: 45-51.

[15] Foerch C, Curdt I, Yan B, Dvorak F, Hermans M, Berkefeld J, Raabe A, NeumannHaefelin T, Steinmetz $H$, Sitzer M. Serum glial fibrillary acidic protein as a biomarker for intracerebral haemorrhage in patients with acute stroke. J Neurol Neurosurg Psychiatry 2006;77: 181-4.

[16] Sulter G, Elting JW, De Keyser J. Increased serum neuron specific enolase concentrations in patients with hyperglycemic cortical ischemic stroke. Neurosci Lett 1998;253: 71-3.

[17] Tiedt S, Duering M, Barro C, Kaya AG, Boeck J, Bode FJ, Klein M, Dorn F, Gesierich B, Kellert L, Ertl-Wagner B, Goertler MW, Petzold GC, Kuhle J, Wollenweber FA, Peters N, Dichgans $M$. Serum neurofilament light: A biomarker of neuroaxonal injury after ischemic stroke. Neurology 2018;91: e1338-e1347.

[18] Kuhle J, Barro C, Andreasson U, Derfuss T, Lindberg R, Sandelius A, Liman V, Norgren $\mathrm{N}$, Blennow $\mathrm{K}$, Zetterberg $\mathrm{H}$. Comparison of three analytical platforms for quantification of the neurofilament light chain in blood samples: ELISA, electrochemiluminescence immunoassay and Simoa. Clin Chem Lab Med 2016;54: 1655-61.

[19] Fisher RS, Acevedo C, Arzimanoglou A, Bogacz A, Cross JH, Elger CE, Engel J, Jr., Forsgren L, French JA, Glynn M, Hesdorffer DC, Lee BI, Mathern GW, Moshe SL, Perucca E, Scheffer IE, Tomson T, Watanabe M, Wiebe S. ILAE official report: a practical clinical definition of epilepsy. Epilepsia 2014;55: 475-82.

[20] Beghi E, Carpio A, Forsgren L, Hesdorffer DC, Malmgren K, Sander JW, Tomson T, Hauser WA. Recommendation for a definition of acute symptomatic seizure. Epilepsia 2010;51: 671-5.

[21] Ferlazzo E, Gasparini S, Beghi E, Sueri C, Russo E, Leo A, Labate A, Gambardella A, Belcastro V, Striano P, Paciaroni M, Pisani LR, Aguglia U, Epilepsy Study Group of the Italian Neurological S. Epilepsy in cerebrovascular diseases: Review of experimental and clinical data with meta-analysis of risk factors. Epilepsia 2016;57: 1205-14.

[22] Reddy RV, Moorthy SS, Dierdorf SF, Deitch RD, Jr., Link L. Excitatory effects and electroencephalographic correlation of etomidate, thiopental, methohexital, and propofol. Anesth Analg 1993;77: 1008-11.

[23] Bielewicz J, Kurzepa J, Czekajska-Chehab E, Stelmasiak Z, Bartosik-Psujek H. Does serum Tau protein predict the outcome of patients with ischemic stroke? J Mol Neurosci 2011;43: 241-5.

[24] Haupt WF, Chopan G, Sobesky J, Liu WC, Dohmen C. Prognostic value of somatosensory evoked potentials, neuron-specific enolase, and S100 for short-term outcome in ischemic stroke. J Neurophysiol 2016;115: 1273-8.

[25] Pujol-Calderon F, Portelius E, Zetterberg H, Blennow K, Rosengren LE, Hoglund K. Neurofilament changes in serum and cerebrospinal fluid after acute ischemic stroke. Neurosci Lett 2018;698: 58-63. 
Figures and tables

\section{Table 1}

\begin{tabular}{|c|c|c|}
\hline Number of patients & $\mathrm{n}=90$ & $\%$ \\
\hline Females & 41 & $(46)$ \\
\hline Males & 49 & $(54)$ \\
\hline Age, yrs median (IQR) & $72(65-80)$ & \\
\hline \multicolumn{3}{|l|}{ Comorbidities } \\
\hline Ischemic heart disease & 14 & $(16)$ \\
\hline Diabetes mellitus & 16 & $(18)$ \\
\hline Smoking & 12 & (13) \\
\hline Atrial fibrillation & 36 & $(40)$ \\
\hline & 49 & $(54)$ \\
\hline $\begin{array}{l}\text { Hypertension } \\
\text { Hyperlipidemia }\end{array}$ & 12 & (13) \\
\hline \multicolumn{3}{|l|}{ Clinical characteristics } \\
\hline Pre $\mathrm{mRS}=0$ & 85 & $(94)$ \\
\hline NIHSS baseline median (IQR) & $18(15-22)$ & \\
\hline Thrombolysis & 69 & $(77)$ \\
\hline Time from arrival (mins) to recanalization median (IQR) & $93(65-142)$ & \\
\hline Successful recanalization & 81 & $(90)$ \\
\hline NIHSS at 24 hours median (IQR) & $8(3-15)$ & \\
\hline & $4(1-13)$ & \\
\hline $\begin{array}{l}\text { NIHSS at day } 3 \text { median (IQR) } \\
\text { NIHSS at discharge median (IQR) }\end{array}$ & $2(0-10)$ & \\
\hline \multicolumn{3}{|l|}{ Radiology } \\
\hline Infarction volume $(\mathrm{ml})$ day 1 median (IOR) & $21(4-60)$ & \\
\hline Infarction volume (ml) day 3 median (IQR) & $20(10-83)$ & \\
\hline Acute symptomatic seizure & 4 & (4) \\
\hline
\end{tabular}

Baseline demographics and stroke risk factors. Functional level prior stroke is given in $\mathrm{mRS}$ score, modified Rankin scale. Successful recanalization means a Modified Treatment In Cerebral Ischemia score (mTICI), of $2 \mathrm{~b}$ or 3. n (\%). NIHSS: National Institutes of Health Stroke Scale. 
Table 2 Clinical characteristics of PSE patients

\begin{tabular}{|c|c|c|c|c|c|c|c|c|c|c|c|c|c|c|}
\hline $\begin{array}{l}\text { I } \\
\text { d }\end{array}$ & $\begin{array}{c}\mathrm{Ag} \\
\mathrm{e}\end{array}$ & $\begin{array}{c}\mathrm{Se} \\
\mathbf{x}\end{array}$ & $\begin{array}{c}\text { IV } \\
\text { T }\end{array}$ & $\begin{array}{l}\text { Anesthesi } \\
\text { a method }\end{array}$ & $\begin{array}{c}\text { Infarctio } \\
\text { n volume } \\
\text { baseline } \\
\text { CT }(\mathrm{ml})\end{array}$ & $\begin{array}{c}\text { Infarctio } \\
\text { n volume, } \\
\text { CT day } 1 \\
\text { (ml) }\end{array}$ & $\begin{array}{c}\text { Infarctio } \\
\text { n volume, } \\
\text { MRI day } \\
3 \text { (ml) }\end{array}$ & $\begin{array}{c}\text { Infarctio } \\
\text { n volume } \\
\text { MRI } \\
\text { day90 } \\
\text { (ml) } \\
\end{array}$ & $\begin{array}{l}\text { NIHSS at } \\
\text { admissio } \\
\text { n }\end{array}$ & $\begin{array}{c}\text { NIHSS } \\
\text { at } \\
\text { discharg } \\
\text { e } \\
\end{array}$ & $\begin{array}{c}\text { Cortical } \\
\text { lesion } \\
\text { MRI } \\
\text { day } 3 \\
\end{array}$ & $\begin{array}{l}\text { ASPECT } \\
\text { S score }\end{array}$ & $\begin{array}{c}\text { Involvemen } \\
\text { t of basal } \\
\text { ganglia }\end{array}$ & $\begin{array}{c}\text { Semiolog } \\
\mathbf{y}\end{array}$ \\
\hline 1 & 83 & $\mathrm{~F}$ & Yes & $\begin{array}{c}\text { Conscious } \\
\text { sedation }\end{array}$ & 1 & 3 & 5 & $\begin{array}{c}\text { New } \\
\text { stroke } \\
\text { involving } \\
\text { the whole } \\
\text { MCA } \\
\text { territory, } \\
\text { right side } \\
\text { (300 ml) }\end{array}$ & 16 & 5 & $\begin{array}{c}\text { Yes } \\
\text { (mostly } \\
\text { parietal } \\
\text { and } \\
\text { temporal } \\
\text { ) }\end{array}$ & $\begin{array}{c}6 \text { (MRI } \\
\text { day 3) } \\
1 \text { (after } \\
\text { new } \\
\text { stroke, } \\
\text { MRI day } \\
90)\end{array}$ & Yes & FIAS \\
\hline 2 & 83 & $\mathrm{~F}$ & No & $\begin{array}{c}\text { Conscious } \\
\text { sedation }\end{array}$ & 37.5 & 90 & 100 & - & 23 & 18 & $\begin{array}{c}\text { Yes } \\
\text { (frontal } \\
\text { and } \\
\text { temporal } \\
\text { lobe) }\end{array}$ & 1 & Yes & FIAS \\
\hline 3 & 70 & $\mathrm{M}$ & No & $\begin{array}{c}\text { General } \\
\text { anesthesia }\end{array}$ & 100 & 230 & 300 & - & 23 & 8 & $\begin{array}{c}\text { Yes } \\
\text { (frontal, } \\
\text { parietal, } \\
\text { temporal } \\
\text { lobe) }\end{array}$ & 0 & Yes & FAS \\
\hline 4 & 70 & $\mathrm{M}$ & Yes & $\begin{array}{c}\text { General } \\
\text { anesthesia }\end{array}$ & 0 & 45 & 17 & - & 21 & 3 & $\begin{array}{c}\text { Yes } \\
\text { (insular } \\
\text { and } \\
\text { temporal } \\
\text { ) }\end{array}$ & 6 & No & FAS \\
\hline
\end{tabular}

Clinical characteristics of PSE patients. F: female, M: male. Successful recanalization: thrombectomy resulting in mTICI score 2b or 3. IVT: Intravenous thrombolysis. NIHSS: National Institutes of Health Stroke Scale. FIAS: Focal impaired awareness seizures. FAS: Focal aware seizures. 


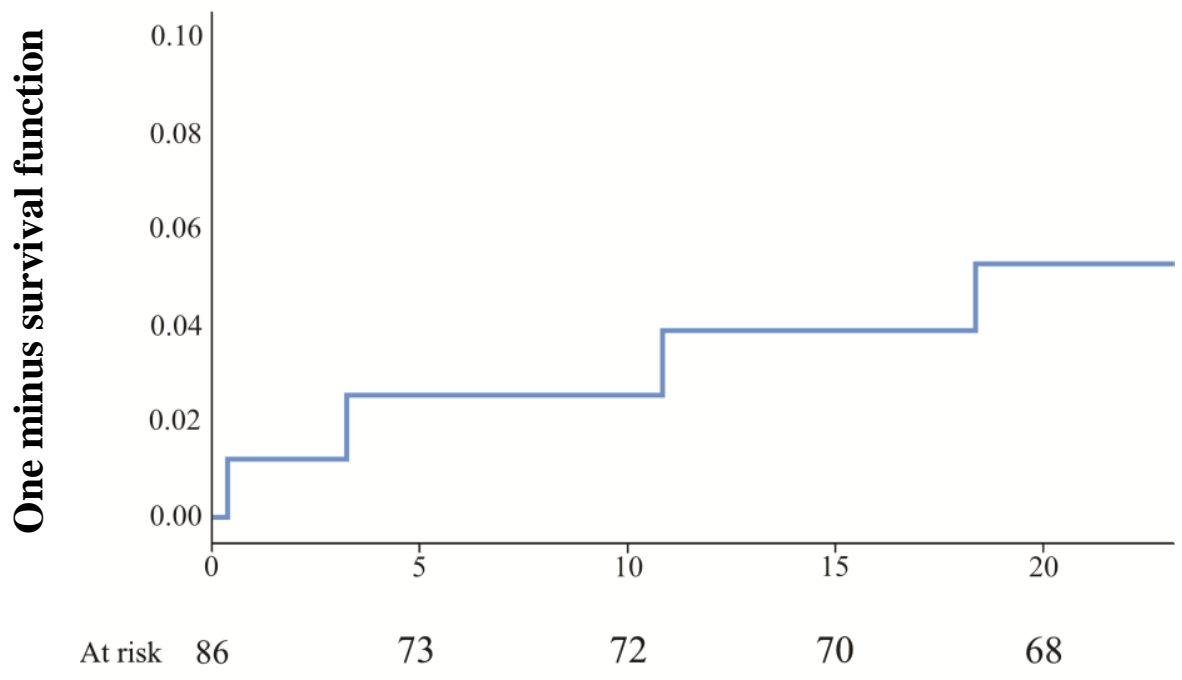

Time (months)

Fig. 1 Kaplan-Meier curve of PSE. Risk of epilepsy = 1 minus epilepsy-free survival. At risk $=$ the number of remaining cases. 



Fig. 2 A - E Concentrations of biomarkers in PSE patients Concentrations for tau (A), NFL (B), GFAP (C), S-100b (D), NSE (E) in patients that developed PSE. 